\title{
Can the Humanities Humanize Health Care?
}

Julet Baltonado, OMS III

Tyler Cymet, DO

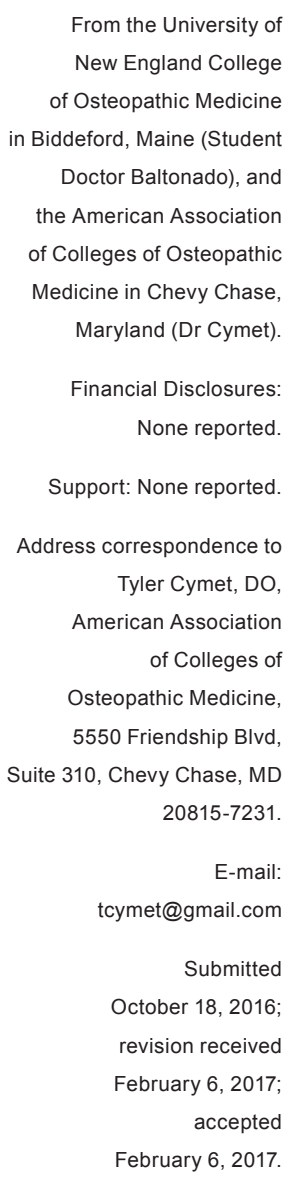

From the University of

New England College

of Osteopathic Medicine

ord, Maine (Student

of Colleges of Osteopathic

icine in Chevy Chase,

ancial Disclosures: \section{.} .

$$
\text { mec }
$$

"To pursue science is not to disparage the things of the spirit. In fact, to pursue science rightly is to furnish the framework on which the spirit may rise."

-Vannevar Bush, D.Eng ${ }^{1}$

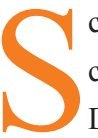
cience can exist without context just as medicine can exist without patients, but should it? Data supporting a need for medical students to learn literature, philosophy, language, religion, art, and music are limited, but study findings indicate that the humanities can enhance empathy in medical students. ${ }^{2}$

Sir William Osler, MD, asked, "Will study of the humanities counter overspecialization and narrowness?" ${ }^{3}$ In osteopathic medicine, one might ask, "Can study of the humanities reinforce the osteopathic philosophy that emphasizes care for the whole person: body, mind, and spirit? How do we develop a better appreciation or understanding of our patients?"

Groups such as the Arnold P. Gold Foundation ${ }^{4}$ and the American Balint Society ${ }^{5}$ formed to focus on enhancing humanism in health care. Meanwhile, osteopathic medical schools are struggling to find the proper structure to teach, assess, and value humanistic qualities in medical education despite the centrality of humanism to the osteopathic philosophy.

Although outlets and structure to study and explore the humanities are limited in medical education, attempts to humanize medicine through narrative medicine, illness narratives, creative writing, and storytelling exist. Physicians have long sought opportunities to share their stories, to illuminate human experiences, and to process those experiences outside of the required training in medicine.

By incorporating skills from the humanities in medical training, we can equip physicians in mindful listening and empathetic and compassionate observation. Osteopathic students and physicians are taught to listen not only to what patients say but also to what they do not say (eg, body language).

\section{Narrative Medicine}

A physician listens to the patient's story in an attempt to understand the illness in context. Greenhalgh and Hurwitz introduced this school of thought in their book Narrative Based Medicine. ${ }^{6}$ Patient narratives, when explored in depth, may help physicians form diagnostic and treatment plans. Narratives can also provide a framework for a more holistic approach to care. ${ }^{7}$

Rita Charon, MD, linked narrative-based studies with clinical practice. Charon defines narrative medicine as "medicine practiced with the narrative competence to recognize, interpret, and be moved to action by the predicaments of others." ${ }^{\prime 8}$ She maintains that training in narrative medicine contributes to improved patient care:

\section{Listening to stories of illness and recognizing that there are often no clear answers to patients' narrative questions demand the courage and generosity to tolerate and to bear witness to unfair losses and random tragedies. Accomplishing such acts of witnessing allows the physician to proceed to his or her more recognizably clinical narrative tasks: to establish a therapeutic alliance, to generate and proceed through a differential diagnosis, to interpret physical findings and laboratory reports correctly, to experience and convey empathy for the patient's experience, and, as a result of all these, to engage the patient in obtaining effective care. ${ }^{9}$}

Narrative medicine skills that are currently taught and used in medical education have the potential to transform clinical practice. ${ }^{10-14}$ The number of graduate programs, seminars, and conferences in narrative medicine continues to rise. ${ }^{15}$ Several dozen medical journals publish narrative, literary, and creative works. ${ }^{16}$ Additionally, many online journals are dedicated to promoting the theory and practice of narrative medicine through original publications, essay contests, and literary readings. ${ }^{17,18}$

Medical students can create opportunities to share medical narratives as a response to the gap between the humanities and medical education. 
Some osteopathic medical schools publish literary journals that are often edited by students to promote awareness of self-care, reflection, and mindfulness and to showcase artistic talents (Table). Through poetry, essays, photographs, prose, videos, and illustrations, medical students, educators, and physicians share personal stories related to medicine and give a voice to perspectives previously untold. These creative spaces emphasize the therapeutic nature of narratives for both the storyteller and the reader.

\section{Art in Medicine}

The observational skills acquired from art observation can be used to enhance clinical skills. Artists who have mastered art observation - many of whom have never studied medicine - can help physicians identify the subtle details of the body and manifestations of illness by training their eyes to see deeper than laboratory and imaging results. Physicians thus may learn to make diagnoses based on their own observations rather than depending solely on tests. ${ }^{19}$

Medical educators have found value in teaching specific humanities skills. In 2012, Dianna Silvagni, JD, at Nova Southeastern University College of Osteopathic Medicine launched the Art Observation Program for students to develop effective skills in observation of patients through discussing artwork and art principles. Students can participate on site or remotely through a virtual version of the art program. Through this awardwinning program, ${ }^{20}$ students have access to artwork from a local art museum and engage in facilitated discussions about art observation principles as they relate to observing patients.

In a project between the Uniformed Services University of the Health Sciences and the National Intrepid Center of Excellence, students participate in art therapy by creating masks to promote selfexploration and personal identity formation and to prevent burnout. ${ }^{21}$ Through this project, students can take a break from clinical and academic commitments and focus on creativity.

\section{Looking Forward}

There is a growing movement to incorporate humanities into medical education. The humanities comprise powerful tools to individualize care for the patient and to provide self-care and support to physicians in a stressful profession. To maximize a patient's health, physicians must look beyond the science and see the individual.

Medical humanities resources are available both inside and outside the osteopathic medical community. ${ }^{22}$ As technology advances, we need to monitor the divide between humanities and medicine as a protection for the patient-physician relationship. Humanities can be a helpful tool to bridge communication gaps and foster unity between patients and physicians.

\section{Table.}

Literary Journals at Osteopathic Medical Schools

\begin{tabular}{lcl} 
School & Journal Name & Journal Website \\
\hline $\begin{array}{l}\text { Des Moines University } \\
\text { College of Osteopathic Medicine }\end{array}$ & Abaton & http://www.dmu.edu/abaton \\
\hline $\begin{array}{l}\text { University of New England } \\
\text { College of Osteopathic Medicine }\end{array}$ & Akesis & http://dune.une.edu/akesis \\
\hline $\begin{array}{l}\text { Ohio University Heritage } \\
\text { College of Osteopathic Medicine }\end{array}$ & ART-ERY & $\begin{array}{l}\text { https://www.ohio.edu/medicine/about/ } \\
\text { offices/student-affairs/student-organizations/ } \\
\text { dublin/him.cfm }\end{array}$
\end{tabular}


Cultural competence and professionalism are topic areas where proficiency is expected, and humanism should be considered a required area as well. The Hippocratic Oath serves as a reminder to physicians, who vow to "remember that there is art to medicine as well as science, and that warmth, sympathy, and understanding may outweigh the surgeon's knife or the chemist's drug." (doi:10.7556/ jaoa.2017.046)

\section{References}

1. Gaither CC, Cavazos-Gaither AE, eds. Gaither's Dictionary of Scientific Quotations. 2nd ed. New York, NY: Springer; 2012:2174.

2. Graham J, Benson LM, Swanson J, Potyk D, Daratha K, Roberts K. Medical humanities coursework is associated with greater measured empathy in medical students. Am J Med. 2016;129(12):1334-1337. doi:10.1016/j.amjmed.2016.08.005

3. Hinohara S, Niki H, eds. Osler's "A Way of Life" \& Other Addresses With Commentary \& Annotations. Durham, NC: Duke University Press; 2001:3-18, 21-29, 63

4. Humanism and medicine lecture at the AAMC Gold Foundation website. http://www.gold-foundation .org/programs/humanism-and-medicine-lecture-at -the-aamc/. Accessed February 21, 2017.

5. Home. The American Balint Society website. http://americanbalintsociety.org/. Accessed February 21, 2017.

6. Greenhalgh T, Hurwitz B, eds. Narrative Based Medicine. London, UK: BMJ Books; 1998.

7. Greenhalgh T, Hurwitz B. Narrative based medicine: why study narrative? BMJ. 1999;318(7175):48-50.

8. Charon R. Narrative medicine: form, function, and ethics. Ann Intern Med. 2001;134(1):83-87. doi:10.7326/0003-4819-134-1-200101020-00024

9. Charon R. The patient-physician relationship. Narrative medicine: a model for empathy, reflection, profession, and trust. JAMA. 2001;286(15):1897-1902.

10. DasGupta S, Charon R. Personal illness narratives: using reflective writing to teach empathy. Acad Med. 2004;79(4):351-356.

11. Johna S, Rahman S. Humanity before science: narrative medicine, clinical practice, and medical education. Perm J. 2011;15(4):92-94.

12. Nowaczyk MJM. Narrative medicine in clinical genetics practice. Am J Med Genetics. 2012;158A(8):1941-1947.

13. Pearson AS, McTigue AP, Tarpley JL. Narrative medicine in surgical education. J Surg Educ. 2008;65(2):99-100. doi:10.1016/j.jsurg.2007.11.008
14. Bregman BM, Irvine C. Subjectifying the patient: creative writing and the clinical encounter. Fam Med. 2004;36(6):400-401.

15. Fioretti C, Mazzocco K, Riva S, Oliveri S, Masiero M Pravettoni G. Research studies on patients' illness experience using the Narrative Medicine approach: a systematic review. BMJ Open. 2016;6(7):e011220. doi:10.1136/bmjopen-2016-011220

16. Tello MA, Reisman A, Manning KD, Hatem D, Branch WT. Writing and the art of medicine: from personal reflection to publication. Presented at: Society of General Internal Medicine National Conference; May 2009; Miami, FL. http://www.documentingmedicine.com/wp-content /uploads/2011/10/Getting-Narratives-published.pdf. Accessed February 8, 2017.

17. Intima. Intima: A Journal of Narrative Medicine website. http://www.theintima.org/. Accessed February 8, 2017.

18. Survive \& Thrive: A journal for medical humanities and narrative as medicine. St. Cloud State University website. http://repository.stcloudstate.edu/survive_thrive/. Accessed February 10, 2017.

19. Ge SM. Observation: the importance of art in medicine. Osler Library and Osler Library Board of Curators Essay Contest. https://www.mcgill.ca/library/files/library/susan _ge_art__medicine.pdf. Accessed February 10, 2017.

20. 2015 Outstanding Advancement in Osteopathic Medical Education Award Winner. American Association of Colleges of Osteopathic Medicine website. http://www.aacom.org /cosgp/i-am-a-do-student/awards/curriculum-award/2015. Accessed February 10, 2017.

21. Unmasking burnout: Art as therapy and self-expression. Uniformed Services University of the Health Sciences; 2016. https://www.usuhs.edu/sites/default/files/media /vpe/pdf/unmasking_burnout_art_as_therapy_and_selfexpressio.pdf. Accessed February 10, 2017.

22. Helpful links. Yale School of Medicine website. https://medicine.yale.edu/humanities/resources /links.aspx. Accessed February 21, 2017.

๑) 2017 American Osteopathic Association 